\title{
The Effect of the Knowledge of Semantic Macro-Structure on the News Report Writing Ability of Iranian Students
}

\author{
Hamidreza Faraji Nejad \\ Department of Foreign Languages, Islamic Azad University, Bandar Abbas Branch \\ E-mail: hamidreza323@yahoo.com \\ Afshin Soori (Corresponding author) \\ Department of Language and Literature, Islamic Azad University, Larestan Branch \\ E-mail: afshin_soori@yahoo.com \\ Abusaied Janfaza \\ Department of Foreign Languages, Islamic Azad University, Bandar Abbas Branch \\ E-mail: s_janfaza@hotmail.com \\ Faranak Faraji Nejad \\ Department of Foreign Languages, University of Isfahan, Iran \\ E-mail: faranak.farajinejad@yahoo.com
}

Received: 05-01-2014

doi:10.7575/aiac.ijalel.v.3n.3p.157
Accepted: 10-02-2014

Published: 01-05-2014

URL: http://dx.doi.org/10.7575/aiac.ijalel.v.3n.3p.157

\begin{abstract}
The current study investigates whether the knowledge of semantic macro-structures, specifically local to news texts have any significant effect on the report writing of advanced learners of English in terms of three main categories of rating, namely structure, vocabulary, and organization. This study is a true experimental design which provides pretest of general proficiency test as well as pretest of writing ability. The experimental group received treatment and the control group received placebo. Finally, the students were provided with a posttest of writing.

The participants of this study were 40 male upper-intermediate Iranian EFL students studying English in two wellknown English institutes of Jahrom, Iran.

After running a preliminary test of general language proficiency, the researcher administered the pretest. Having used a t-test, the researcher found that there was no significant difference between the subjects' reports vocabulary, structure, and organization quality across groups of control and experimental.

After the treatment program, the researcher administered a post test, containing 5 more news texts. After collecting the papers, he asked the raters to rate them. Finally, using t-test, the researcher found that the knowledge of semantic macro-structures specifically local to news texts had significant effect on the organization quality and vocabulary quality of the learner's report sheet but it failed to have any significant effect on the structure quality of his report sheet.
\end{abstract}

Key words: Macrostructure, Macro rules, Semantic macro structure, News report, Writing ability

\section{Introduction}

A macrostructure is defined as a theoretical reconstruction of intuitive notions such as topic or theme of a discourse (VanDijk, 1985). Macrostructure tries to explain some relevant and important issues in the semantic information of the discourse. The global coherence of a discourse is also described by the macrostructure. It seems that there would be no overall control upon the given local coherence criteria without such a global coherence.

Semantic information that gives an overall unity to a discourse is expressed by the macrostructure. Text itself expresses the underlying macrostructures. Examples of the texts are titles, summaries or the expression of plans for action (VanDijk, 2003).

Macrostructure of a discourse is one of the important functions of respective meanings of the sentences that is expressed by the fundamental principle of semantics. At the same time, the sum of all pair wise coherence links between sentences is not given by an added connectivity at the local level of the sequence. In other words, it can say macrostructure is a kind of semantic transformation that map the sequences of propositions the text on sequences of macro propositions at more abstract, general, or global levels of meaning. Propositions are selected, generalized, and reconstructed into fewer more general, or more abstract propositions by such mapping. In general, macro-rules are these transformations or operations. Macro-structures are second-order semantic interpretation rules. After the sentence pairs are interpreted, further interpretation of sequences as global propositions are allowed and as a whole this characterize the meaning of a sequence or discourse(van Dijk, 2003). 
Semantic mapping rules or transformations which connect higher level macro propositions to lower level propositions are macro rules. The rules are basically simple techniques aiming at data reduction and are applied iteratively and recursively. They are applied in a qualitative approach in which the expressed opinions are interpreted in a textual context, classified and organized according to the theoretical framework presented in the research project at hand.

There are basically four macro rules:

1.Keep words, phrases or sentences because they are evaluated as relevant.

2.Delete (in fact ignore) words, phrases or sentences, not physically, but marked as less relevant ornot relevant. 3.Generalize words, phrases and/or sentences, that is reformulated at a higher abstraction level. 4.Construct new words or phrases, for instance when a set of phrases extracted from the text is annotated with the semantic code (for instance with a code signaling the interpretation 'ethical argument').

A macro proposition may either be formulated as a highly representative sentence summarizing a series of sentences or it may be formulated as a set of original sentences extracted from the source text. Theoretically it is assumed that the whole macrostructure has a hierarchical organization, in which each set of macro propositions (derived from a set of underlying propositions), can be subsumed under a higher level macro proposition. The ordering of expressed propositions at the lower levels is implicitly defined by the ordering of macro propositions at each level. However, it causes some problems for a recognized representation of relevant expressed opinions. There is a definition for the ordering of text. This definition is considered by relevance of topic (most important topic come first) rather than by some chronological order of topics. Longer texts usually deal with several not directly related topics and may therefore be abstracted to several macrostructures. "Macrostructures have a cognitive nature. Macrostructures have a subjective nature since different language users may find different information in the text more important." (Van Dijk 1985, p.33).

A piece of text as a coherent whole will be affected by World knowledge (Van Dijk 1985). The link between sentences may involve conditions, causes, or reasons, and these indicate that how events or situations in the world are organized (Van Dijk 1985). As already stated, an understanding of how language is used in the text is a prerequisite for identifying, extracting and representing the meaning. This understanding can be achieved by a close study of the situations and activities where words and phrases are/were used.

Obviously, the world knowledge or beliefs may be different for writer and reader, and therefore Van Dijk (1985) argues that local coherence also may be subjective: Propositions may cohere for the writer but not for the reader. This theory of coherence has clear implications for the text analytical approaches since the writer presupposes vast amounts of social and political knowledge. Werth (1999) postulates that coherence is not inherent in text, rather the reader of the text constructs coherence. In order for the writer and reader to share a common perception of coherence, the writer and reader have to share some common ground of knowledge, where common ground is defined as:"...the totality of information which the speaker(s) and hearer(s) have agreed to accept as relevant for their discourse." (Werth, 1999, p.125).Regarding the upper mentioned issue, this study is supposed to explore whether the knowledge of semantic macro-structures, specifically local to news texts have any significant effect on the report writing of advanced learners of English in terms of three main categories of rating, namely structure, vocabulary, and organization. In line with the aim of the study, the researcher presents the following research question:

1. Does the subjects' knowledge of semantic macro-structure of the news texts improve news text report writing?

2. Does the subjects' knowledge of semantic macro-structure of the news texts have any significant effect on structure and usage ability of the learner's news text report writing?

3. Does the subjects' knowledge of semantic macro-structure of the news texts have any significant effect on the organization ability of the learner's news text report writing?

4. Does the subjects' knowledge of semantic macro-structure of the news texts have any significant effect on vocabulary ability of the learner's news text report writing?

\section{Review of Related Literature}

If we look at the learner's attempts to create textual patterns of the kinds described in the previous section, we find that there are sometimes problems (McCarthy, 2005). In fact, such difficulties are reflected in the learners' writing skill.

What is most observable in the learners' data is that, although the overall patterning is present, misuse of signaling words can disorient the reader somewhat. The following extract is from a summary of a text on the problems of training astronauts to live in space (McCarthy, 2005, p.163):

"As soon as a man of our century realizes we're going to reach the complete control of communicating and travelling in space, he has to consider the huge number of difficulties that overcome with the developing of space travels. Science and technique may develop to hinder a lot of problems, like for example, loss of oxygen, intense cold, severe radiation bursts and so on."

The first infelicity in the discourse-signaling vocabulary occurs when "difficulties and overcome", but here, it is not entirely clear whether the problem is lexical; it may be interference from a cognate from in Italian which hides a false friend or it could be syntactic, insomuch as many languages use a "that" construction where English would have an infinitive ("difficulties to overcome"), but the vocabulary choice tends to be dominated by the quite plausible syntax here, and most readers presented with the text suffer disorientation. The second error "to hinder a lot of problems" is more obviously lexical and underlines a point made earlier in the previous section regarding grouping words together along discourse-functional lines, and suggests a role for the teaching of collocating pairs in the case of such words. 
Other examples are observed in the written texts of learners who are not familiar with such macro-level structures and their associated collocation. For example, "interfere to solve a problem" is observed by the researcher during this study. In English one "intervenes", rather than "interferes" to solve a problem.

In a study, McCarthy (1995), found that discourse patterns such as problem solution patterns from their L1 to L2 can be transferred well by English learners. The problems are rooted from their linguistic competence or lexico-grammatical level. But what about the writing of learners who are culturally different form Western ones? Are there established norms of writing in other literate cultures that are different and might be expected to interfere with macro-level decision making of the learner writing in English?

Kaplan (1996) found that English texts were linear and hierarchical, where as Semitic and Arabic ones were characterized by parallelism'; oriental texts had indirection as a characteristic. According to McCarthy (2005), what we find frequently in examining Middle Eastern, oriental, and other learner data in English are the same problems noted above that bad discourse organization often accompanies poor lexico-grammatical competence. For example, in a study, McCarthy (2005) found that a Japanese low-level learner's text contained inadequacies with respect to macro-level structure:

British teenagers watching television. Boys and girls many people. My country teenagers very more people watching television, because my country television more select. My country TV have channel no. 1,3,4,6,8,10,12.

British teenagers playing football very famous. But my country teenagers playing baseball very famous.

McCarthy (2005) suggests that such macro-patterns can be taught through chaining and text-jigsaw activities. Teaching writing would be an easy task provided that second language learners easily know how to write things down. In fact, learning to write even in one own mother tongue is not the matter of writing things down. There is in fact a distinction between mechanical aspects of writing and more sophisticated more communicative aspects.

In another study concerning news texts, news structure in the press is analyzed by Schmitt et al. (2005).Based on VanDijkin work, in the news discourse the thematic and schematic structure are focused by the news structure. In order to check the applicability of Dijk's analytic framework for the analysis of news discourse structures in the media a case study has been performed. The theoretical model of Van Dijk's discourse analysis can be also applicable to the structure of Brazilians news. Journalists in the elaboration of news and readers in the text comprehension process would be under the application of thematic and schematic structures. It seems that none of the definitions about classic journalism indicates its study objective. In this way, in modern journalism news is defined, "the enunciation of a series of facts emanating from a most important or relevant fact; and from each fact, emanating from the most important or relevant aspect." (Van Dijk, 1981)

The global structures include topics or themes and the superstructure scheme. "The general organization of global 'topics' upon which verse a news example" being the thematic analysis performed under the illumination of a semantic macrostructure theory. Those "constitute the formal representation of the global content of a text or dialogue and so characterizing part of a text meaning. Schematic structures, on the other hand, are used to describe the global form of a discourse, being theoretically called as superstructures"(Van Dijk, 2004, p. 122-123).

In another study,themacrostrucutral processing of multiple text passages is addressed by Lacroix (1999). She identified two stages of macrostructuralconstruction and organization during complex text comprehension. The impacts of different textual and situational factors on macrostructural construction and organization were examined in three experiments. The students were supposed to read small text documents that were prepared in hyper text format. After analyzing the students' reading strategies and written reports, she found that macrostructural organization were under the influence of headlines and presentation format. She also found that both levels of macrostructural processing were affected by marking important information and the presentation order. In this study, however, the researcher investigates the effects of such rules on the writing ability of the language learners based on comprehending news texts. In fact, such texts have been analyzed in terms of macrostructures by Schmitt et.al. (2005)

\section{Design of the study}

The design of the current study is the experimental design. The researcher tests the hypothesesby reaching valid conclusions about relationships between independent and dependent variables. In fact, the design of the study was selected based on the purpose(s) of the study. Moreover, the design tells us how the variables are controlled or manipulated and how the subjects are to be assigned to the experimental and control groups. There are three types of experimental designs (Best and Kahn, 2006). This study is true experimental design which provides pretest of general proficiency test as well as pretest of writing ability. The experimental group received the treatment and the control group received the placebo and finally a posttest of writing.

\subsection{Subjects}

This study was carried out in Jahrom. The subjects were selected from two well-known English institutes of Jahrom. There were initially 60 subjects who were all studying at the advanced level in the institutes. Having run initial tests, only 40 subjects were selected and placed into two groups of experienced and control. Age was not a variable and all the subjects were males. 


\subsection{Instrumentation}

To test the hypothesis, namely the subjects' knowledge of the news semantic macro-structure does not have a significant effect on developing their task based writing; the researcher used the followinginstrumentsto collect data:

- $\quad$ General proficiency test: In order to select a specific homogenous sample of subjects, the researcher selected a general test of proficiency to administer as the first tool of the study. The test contained three parts of structure and written expression, reading comprehension, and vocabulary. It contained 80 questions and the subjects were given 80 minutes to complete the test. It is pressing to note that only those subjects with 1 standard deviation over the mean were chosen to take part in the study.

- Writing task (pre-test): since purpose of the research was specifically aimed at writing in a task-based environment, the pre-test of writing was designed likewise, concentrating on the news texts. The researcher used a sample of news texts including major current headlines and the subjects were asked to write a report about each news texts. Five news texts were selected and five reports were collected from each subject. (Appendix B)

- $\quad$ Treatment program: the treatment program lasted for a period of 16 sessions. In order to motivate the subjects to participate in the program, the researcher told the subjects that the course of writing has just opened up and it is totally free for the participants. However, a pre-test of general proficiency and pretest of writing are in order. During the treatment program, the researcher taught the experimental group, semantic-macro rules as mentioned in the previous section. He also provided them with assignments accordingly. A sample of a session of treatment program is available for the reader here (Appendix C)

- The placebo program for the control group involved a classic course for writing reports based on available materials such as "reading how to write", "paragraph writing", "study skills" and "sentence writing". The researcher merely worked on the sentence grammar, rules of writing paragraphs and making reports.

- $\quad$ Post-test writing: this test was designed to evaluate the result of the treatment or program and compare it to the control group. It involved writing reports about some major current news texts selected from Tehran Times. For the purpose of this study, 5 news texts were selected and were presented as the post-tests. The subjects were asked to provide a summary of each text in line with the content of the sessions they had participated during the period of 16 sessions. A sample of the news texts and the subjects' reports are recorded in appendix (D)

\subsection{Procedure}

In order to test the null hypothesis, the following steps were taken by the researcher:

- Initially, the researcher searched for the most prestigious English Institutes in Jahrom and selected two of them. Having talked to each institute officials and received clearance for running the research there; he selected three advanced classes in each institute and ran the general proficiency test there (see, Appendix B). The subjects were told that the tests were part of their class activities. The pre -test was designed into an e-mail and sent to each selected subject for the sake of the convenience. It is pressing to note that only a few subjects (10 in the entire 60) did not have e-mail address, hence they followed up the program the old fashion way. The pre-test contained report writing on the basis of a selected news text.

- Having selected the subjects and designated the control and experimental groups, the researcher spent 16 sessions for the treatment program and placebo. Throughout the treatment program, the researcher presented semanticmacro rules reflected in the news texts. The medium of instruction was English and the sessions followed assignments for the students to complete as homework. At the same time, for a period of 16 sessions, the control group was exposed to a writing program which contained sentence making, paragraph writing and report writing.

- $\quad$ Finally, after the assigned sessions, a post-test was carried out. The test reflected report writing about news texts.

\subsection{Analysis of Data}

In this study the researcher tested the hypotheses. To this end, he carried a series of statistical procedure, namelyt-test.

\section{Results}

Having rated the pre-test, the researcher ran a preliminary t-test in order to see if the mean scores of both control and experimental groups belonged to the same population. In other words, the researcher tried to find if there was any significant difference among the subjects' report writing performance prior to the program.(Table. 1).

Table 1. t-test for pretest

Paired Differences

Mean SD SEM

$95 \% \quad$ Confidence

$\mathrm{t}$

\begin{tabular}{lllllllll} 
& & Interval & of & the & Difference & $\mathrm{df}$ & \multicolumn{3}{c}{$\begin{array}{l}\text { Sig. (2-tailed) } \\
\text { Sean }\end{array}$} & & & & & SD & & SEM \\
\hline \multirow{2}{*}{ Lower } & Upper & Lower & Upper & Lower & Upper & Lower & Upper \\
& .06667 & .9071 & .16563 & -.27208 & .40542 & .403 & 29 & .690 \\
\hline
\end{tabular}


As observed from the analysis, the lower and the upper limits include 0 , hence, $\mathrm{m} 1=\mathrm{m} 2$.In other words, there was no significant difference between the control group and experimental group with respect to their performance on pretest.

Having standardized the scales, the researcher computed the inter-rater reliability according to Ebel (1979). Through this method, the researcher summed the ratings by computing coefficient alpha:

$$
a=\frac{\overrightarrow{F i}}{k i-1}\left(1-\frac{392 i}{B 2 x}\right)
$$

$\mathrm{K}$ is the number of raters (4), $\mathrm{s}^{2} \mathrm{i}$, is the variance of the ratings for a given rater (4 raters, 4 variance values), thus $\mathrm{S} \mathrm{s}^{2} \mathrm{i}$ is the sum of variances of all raters, and $\mathrm{s}^{2} \mathrm{x}$ is the variance of the summed ratings. Having run the inter-rater reliability on the data collected through the ratings, the researcher found that $\mathrm{a}=.85$.

Next, the researcher ran the treatment program and the placebo for a period of 16 sessions. During this period, the subjects in the experimental group worked on news texts by writing reports using VanDijk's macro-structures as mentioned above. They were also given homework assignment in line with the macro-structures. They were asked to mark such structures in the news texts and then write a summery for each part and finally weave those summaries together and provide a final report for each news text. The subjects in the control group, however, were basically taught skills of summery writing available in study skills materials.

After the treatment program, the researcher administered the post-test. The post-test consisted of three news texts for which the students were supposed to write three reports. Having collected the reports, the researcher used the same rating technique as he once did for the pre-test. The same raters rated the reports using the same rating scale. In order to test the research hypotheses, the researcher compared each section of the rating scale separately across control and experimental groups. In other words, the researcher carried out three separate t-tests ${ }^{1}$ for sentence structure, organization, and vocabulary reflected in the rating scale.

Firstly, the researcher investigated the effect of knowledge of semantic macro structure on the quality of report writing with respect to structure section of the rating (Table 2).

Table 2. Two sample t-test for the sentence structure section of the rating scale

\begin{tabular}{llllll}
\hline $\mathrm{N}$ & Mean & St. Dev. & SE Mean & $\mathrm{T}$ & Sig. level(2-tailed) \\
\hline 20 (exp.) & 16.5 & 1.19 & .27 & 1.37 & .18 \\
\hline 20 (cont.) & 16.05 & 1.23 & .25 & & \\
\hline
\end{tabular}

Figure 1 graphically presents the areas of probability of the rejection of the hypothesis for this particular section of the rating.

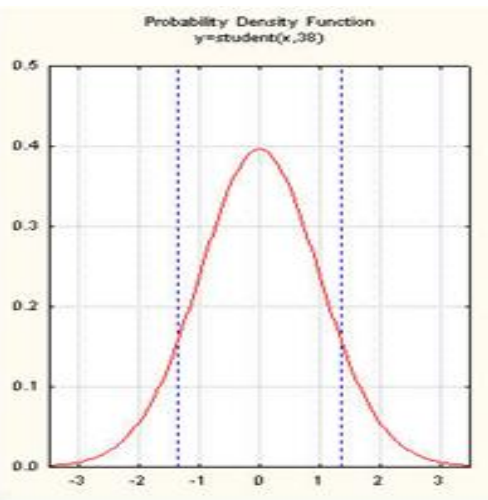

Figure 1. probability density function

The obtained value failed to exceed .05 level of significance; hence, the researcher failed to reject the first null hypothesis, therefore, no significant difference was found between control and experimental groups with respect to sentence structure section of the ratings. In other words, knowledge of semantic macro-structures did not have any significant effect on the sentence-structure quality of the news text report writing. Next, the researcher addressed the organization section of the rating. (Table. 3 )

Table 3. Two sample t-test for the organization section of the rating scale.

\begin{tabular}{llllll}
\hline $\mathrm{N}$ & Mean & St. Dev. & SE Mean & T & Sig. level(2-tailed) \\
\hline 20 (exp.) & 16.55 & 1.93 & .43 & 3.69 & .001 \\
\hline 20 (cont.) & 14.2 & 2.09 & .47 & & \\
\hline
\end{tabular}

\footnotetext{
${ }^{1}$ It is pressing to note that all three t-tests were of tow-tailed type of significant level.
} 
The obtained value, .001 is lower than .05 level of significance. Hence, the researcher rejected the second null hypothesis; therefore, there was a significant difference between control and experimental groups with respect to the organization section of the ratings. In other words, knowledge of semantic macro-structures had a significantly positive effect on the organizational quality of the news text report writing. Figure 2. graphically presents the areas of probability of the rejection of the hypothesis for this particular section of the rating.

Probability Density Function $y=$ student $(x, 33)$

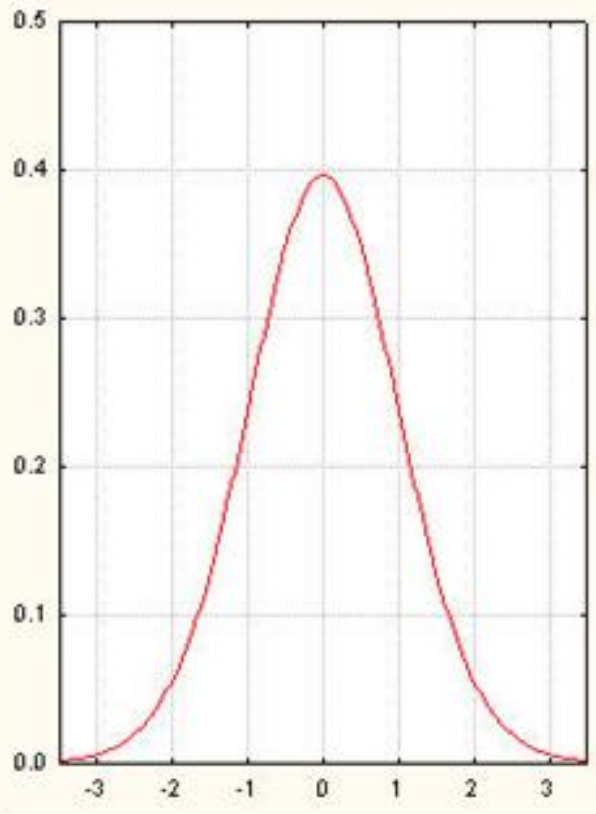

Figure 2. Probability density function

Finally, the researcher addressed the vocabulary section of the rating. (Table, 4)

Table 4. Two sample t-test for the vocabulary section of the rating scale.

\begin{tabular}{llllll}
\hline $\mathrm{N}$ & Mean & St. Dev. & SE Mean & $\mathrm{T}$ & Sig. level(2-tailed) \\
\hline 20 (exp.) & 16.9 & 1.62 & .36 & 3.2 & .003 \\
\hline 20 (cont.) & 15.5 & 1.1 & .25 & & \\
\hline
\end{tabular}

The obtained value, .003 is lower than .05 level of significance. Hence, the researcher rejected the third null hypothesis; therefore, there was a significant difference between control and experimental groups with respect to the vocabulary section of the ratings. In other words, the knowledge of semantic macro-structures had a significantly positive effect on this quality of the news text report writing. Figure 3. graphically presents the areas of probability of the rejection of the hypothesis for this particular section of the rating.

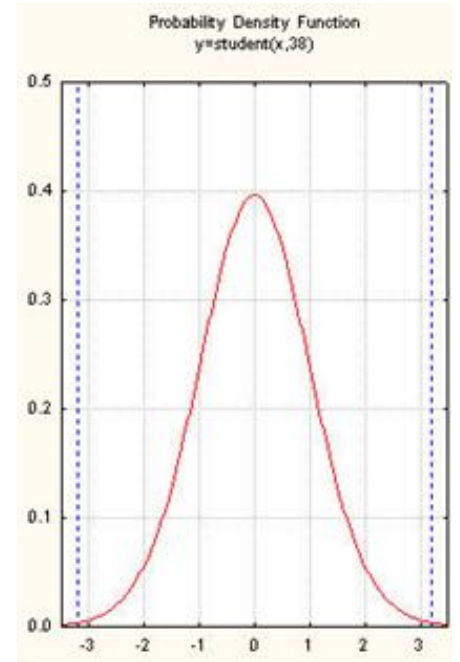

Figure 3. probability density function 
Having tested all null hypotheses using t-test, the researcher concluded that the knowledge of semantic macro structure of the new texts had positively significant effect on the quality of vocabulary and organization of the subjects' reports of the news texts; nevertheless, such knowledge had no significant effect on the quality of structure of the subjects' reports on the news texts.

\section{Conclusion}

Having administered selected subjects by administering the pretest and making sure that they belong to the same population regarding their performance on report writing of news texts, the researcher ran the treatment program during which the subjects in experimental group were taught how to analyze and interpret the news texts according to macro rules. They were also given assignments and other related activities. Nevertheless, the subjects in the control group were simply taught general report writing techniques reflected in study skill materials.

After administrating the post test which contained five news texts the subjects in both experimental and control groups were asked to write their reports. Next, the researcher asked five raters to rate the papers in terms of structure, organization, and vocabulary. Next, using t-test for each category, the researcher tested three hypotheses he considered earlier. He found that as far as the structure section is concerned, there was no significant difference between the subjects in control and experimental groups. However, the subjects in control and experimental groups were significantly different in terms of organization and vocabulary sections of their report ratings. In fact, the subjects in the experimental group performed significantly better than subjects in control group. In other words, the knowledge of semantic macro-rules of news text had significantly positive effect on the improvement of the vocabulary and organization sections of their ratings.

\section{References}

Branden, K. (2006). Task-Based Language Education: From Theory to Practice. Cambridge: Cambridge University Press.

Dörnyei, Z. (1994). Motivation and motivating in the foreign language classroom. Modern Language Journal, 78 (1), PP. 273-284.

Ellis, R (2003). Task-based language learning and teaching. Oxford University Press.

Fairclough, N. (2001). Language and Power, 2nd. edn. London: London.

Fraser, B. J. (1991). Two decades of classroom environment research. In B. J. Fraser \& H. J. Walberg (Eds.), Educational environments: Evaluation, antecedents and consequences (pp. 3-27). Oxford: Pergamon Press.

Gardner, R. C. (1985). Social psychology and second language learning: The role of attitudes and motivation. London: Edward Arnold.

Hadley, A. O. (2004). Teaching Language in Context. New York: Heinle and Heinle Publishers.

Hallin, D. (1997). Sound Bite News. In S. L. (ed), Do the Media Govern? Thousand Oaks: Sage.

Hoey, M. (1983). On the Surface of Discourse. London: Allen and Unwine.

Johnson, K. (2003). Designing Language Teaching Tasks. Hampshire: MacMillan.

Kaplan, R. (1966). Cultural Thought Patterns in Intercultural Education. Language Learning 16(2) , PP. 1-20.

Van Dijk, T. (1985). Handbook of discourse analysis. London. Academic Press

Van Dijk, T. (2003). Superestruturas. Retrieved January 2, 2003, from

http://dialogica.com.ar/unr/redaccion1/unidades/unidad3/archives/000341.htmlVan Dijk (2004)

Werth, P. (1999). Text Worlds: Representing Conceptual Space in Discourse. New York: Longman. 